\title{
Group B Streptococcus Promotes Oxygen Radical-Dependent Thromboxane Accumulation in Young Piglets
}

\author{
LORI A. SHOOK, THOMAS H. PAULY, STEPHEN L. MARPLE, SANDRA J. HORSTMAN, H-H. TAI, \\ BRUCE D. BOWDY, AND MARK N. GILLESPIE
}

University of Kentucky A.B. Chandler Medical Center, College of Medicine, Department of Pediatrics, Division of Neonatology, and College of Pharmacy, Division of Pharmacology and Toxicology, Lexington, Kentucky 40536

\begin{abstract}
Both thromboxane $A_{2}$ and oxygen-derived free radicals appear to play central roles in group $B$ streptococcus (GBS)-induced pulmonary hypertension in piglets. This study tested the hypothesis that GBS promotes oxygen radical-dependent thromboxane accumulation and pulmonary hypertension in infant piglets. Piglets 4-12 d old were anesthetized and prepared for assessment of pulmonary arterial pressure and arterial blood gases. In control animals, GBS $\left(10^{8}\right.$ organisms $/ \mathrm{kg} / \mathrm{min}$ for $\left.15 \mathrm{~min}\right)$ increased mean pulmonary artery pressure by $30 \pm 1.5$ torr and reduced arterial $\mathrm{PO}_{2}$ by $100 \pm 20$ torr. Thromboxane $A_{2}$, radioimmunoassayed in venous blood as thromboxane $B_{2}$, increased by $2452 \pm 800 \mathrm{pg} / \mathrm{mL}$. A second group of piglets was treated with dimethylthiourea (DMTU: 750 $\mathrm{mg} / \mathrm{kg}$ ), a putative oxygen radical scavenger. In these animals, GBS increased pulmonary arterial pressure by only $7 \pm 1$ torr and reduced arterial $\mathrm{PO}_{2}$ by a modest $10 \pm$ 8 torr. Importantly, thromboxane $B_{2}$ content in venous blood failed to increase above control levels in DMTUtreated animals. The protective effects of DMTU in GBStreated piglets could not be ascribed to inhibition of cyclooxygenase or thromboxane synthase because the oxygen radical scavenger failed to attenuate increases in pulmonary arterial pressure and venous thromboxane $B_{2}$ content or reductions in arterial $\mathrm{PO}_{2}$ caused by i.v. infusions of arachidonic acid. DMTU also did not ameliorate pulmonary hypertension evoked by the thromboxane mimetic U44069, thereby suggesting that the scavenger did not act as an end-organ antagonist of thromboxane receptors. These observations suggest that GBS promotes accumulation of thromboxane $A_{2}$ and attendant pulmonary hypertension through an oxygen radical-dependent mechanism. (Pediatr Res 27: 349-352, 1990)
\end{abstract}

\section{Abbreviations}

Ppa, mean pulmonary arterial pressure DMTU, dimethylthiourea GBS, group B streptococci cfu, colony-forming unit

In recent years the chemical mediators of GBS-induced pulmonary hypertension and arterial hypoxemia in infant piglets

Received June 19, 1989; accepted November 17, 1989.

Correspondence and reprint requests: Mark N. Gillespie, Ph.D., University of Kentucky, College of Pharmacy, Division of Pharmacology and Experimental Therapeutics, Lexington, KY 40536.

Supported in part by grants from the National Institutes of Health (HL-36404, HL-38495, and an RCDA to M.N.G., HL-02055), the Cystic Fibrosis Foundation, and the Kentucky Affiliate of the American Heart Association. have come under increased scrutiny. Multiple lines of evidence point to products of arachidonic acid metabolism, both thromboxane $\mathrm{A}_{2}$ and sulfidopeptide leukotrienes, as important participants in the adverse cardiopulmonary response (1-4). Studies in our laboratory indicate that DMTU, a scavenger of hydroxyl radical and, at higher doses, hypochlorous acid $(5,6)$, suppresses GBS-induced pulmonary hypertension and arterial hypoxemia in young piglets (7), thereby suggesting that toxic oxygen radicals also participate in this model of sepsis-related pulmonary dysfunction. These two lines of evidence raise the question as to whether generation of oxygen radicals and eicosanoids in the setting of GBS sepsis may be functionally interrelated. That oxygen radical free generation may lead to production of arachidonic acid metabolites is supported by previous reports showing that $\mathrm{N}$-acetylcysteine, an oxygen radical scavenger that also directly influences neutrophil function, suppresses endotoxininduced accumulation of thromboxane $B_{2}$ and prostaglandin $F_{2 \alpha}$, as well as development of edematous lung injury in intact, adult sheep (8).

In view of the above considerations, our study tested the hypothesis that GBS promotes oxygen radical-dependent accumulation of thromboxane $A_{2}$ in infant piglets. We reasoned that if this hypothesis is valid, then a scavenger of oxygen radicals, specifically the hydroxyl radical scavenger noted above, DMTU, should suppress GBS-induced accumulation of thromboxane $\mathrm{B}_{2}$ and prevent attendant increases in mean Ppa and arterial hypoxemia. Additional experiments were conducted to verify that DMTU does not act as a cyclooxygenase or thromboxane synthase inhibitor or as a thromboxane receptor antagonist in the pulmonary circulation.

\section{MATERIALS AND METHODS}

Animal model. Twenty-five infant piglets unselected as to gender and ranging in age and weight from 5-14 d and $2-4.5 \mathrm{~kg}$, respectively, were used in these studies. Animals were anesthetized with sodium pentobarbital $(30 \mathrm{mg} / \mathrm{kg}$ intraperitoneally) and placed on a heat-exchanging pad to maintain body temperature at $38 \pm 11^{\circ} \mathrm{C}$. Catheters were introduced into the femoral artery and vein for measurement of mean systemic arterial pressure and administration of pharmacologic agents, respectively. Mean Ppa was measured from a specially formed polyethylene catheter inserted into the right evternal jugular vein and advanced into the pulmonary artery. Mean systemic arterial pressure and Ppa were monitored using Statham pressure transducers (Gould, Inc., Oxnard, CA) zeroed at midthoracic level and a Grass polygraph (Quincy, MA). Arterial blood gases were determined in $1.0-\mathrm{mL}$ samples taken from the femoral arterial catheter using an Instrument Laboratories blood gas analyzer (Lexington, MA). 
After catheter introduction, a tracheostomy was performed and the animals were connected to a Harvard small animal ventilator (Harvard Apparatus Co., Inc., South Natick, MA). The animals were then paralyzed with pancuronium bromide $(0.75 \mathrm{mg} / \mathrm{kg}$ i.v. followed by supplemental doses of $0.4 \mathrm{mg} / \mathrm{kg}$ as needed) and ventilated at 45 breaths/min with a mixture of $30 \%$ $\mathrm{O}_{2}$ in $\mathrm{N}_{2}$ using a tidal volume of $7 \mathrm{~mL} / \mathrm{kg}$. At the outset of a $20-$ min acclimitization period, ventilator settings were adjusted to attain baseline arterial $\mathrm{PO}_{2}, \mathrm{PCO}_{2}$, and $\mathrm{pH}$ of approximately 100 torr, 40 torr, and 7.4, respectively, and were not changed during the subsequent experimental protocols.

Bacterial preparation. Cultures of GBS (Streptococcus agalacticae, serotype II, American Type Culture Collection no. 13813, Difco Laboratories, Detroit, MI) were inoculated in brain-heart infusion broth containing $7 \%$ heat-inactivated FCS and grown to $\log$ phase. The medium was centrifuged at $2000 \times g$ for 15 min and the pellet washed and resuspended in Hanks' balanced salt solution. Concentration of bacteria in the slurry was determined by quantitative culture and by relating OD to cfu. GBS was administered to the piglets as a 15 -min i.v. infusion of $10^{8}$ $\mathrm{cfu} / \mathrm{kg} / \mathrm{min}$. Inoculums were routinely tested for purity.

Thromboxane $B_{2} R I A$. The concentration of thromboxane $\mathrm{A}_{2}$ in blood was estimated by RIA of its stable degradation product, thromboxane $B_{2}$. Blood samples $(1.0 \mathrm{~mL})$ were collected into tubes containing $2 \mathrm{mg}$ EDTA and $1 \mu \mathrm{M}$ indomethacin (Sigma Chemical Co., St. Louis, MO) and stored on ice. Subsequently, they were centrifuged and the plasma frozen at $-70^{\circ} \mathrm{C}$ until extraction and RIA by previously-described methods (9). All assays were performed in duplicate.

Vasoactive agents. In addition to GBS, two other stimuli were used to elevate pulmonary arterial pressure in infant piglets. Arachidonic acid (Nu Cek Prep, Eliasan, MN) was delivered as an i.v. infusion of $5 \mathrm{mg}$ over a 2-min period. Changes in Ppa and arterial $\mathrm{PO}_{2}$ were monitored during the infusion and for 20 min thereafter. Some animals received i.v. injections of $1 \mathrm{mg} / \mathrm{kg}$ indomethacin before administration of arachidonic acid to confirm the role of cyclooxygenase in hemodynamic and blood gas changes. The stable thromboxane mimetic U44069 (10), obtained from the Upjohn Co. (Kalamazoo, MI), was administered as i.v. infusions of 100 and $300 \mathrm{ng} / \mathrm{kg} / \mathrm{min}$. DMTU (Aldrich Chemicals, Milwaukee, WI) was dissolved in saline and administered intravenously at a dose of $750 \mathrm{mg} / \mathrm{kg}$ over a 20 -min period, as employed in previous studies (7).

Statistical analysis. Data are presented as the mean \pm SEM. Time and experimental group-dependent differences between mean values were assessed using a two-way analysis of variance combined with Neumann-Kuels test when appropriate. $p \leq 0.05$ were considered to denote statistical significance.

\section{RESULTS}

Changes in Ppa and $\mathrm{PO}_{2}$ evoked by GBS in control piglets and in piglets treated with DMTU are shown in Figure 1. In these studies, infusion of DMTU or its vehicle was initiated $10 \mathrm{~min}$ prior to infusion of GBS and continued for $10 \mathrm{~min}$ into the 15 min infusion of GBS. As expected, GBS promoted significant increases in Ppa that persisted for at least 5 min after termination of the bacterial infusion. Similarly, arterial $\mathrm{PO}_{2}$ dropped substantially after GBS infusion. Baseline Ppa did not differ from controls in piglets receiving DMTU, but baseline arterial $\mathrm{PO}_{2}$ was, for unexplained reasons, slightly lower in the treated animals. Consistent with our previous observations (7), DMTU significantly inhibited both the increase in Ppa and the decline in arterial $\mathrm{PO}_{2}$ normally caused by GBS infusion.

As reported by others (1-3), GBS infusion was associated with profound increases in blood thromboxane $\mathrm{B}_{2}$ content (Fig. 2), which were apparent both during and 5 min after termination of the GBS infusion. In contrast, although baseline thromboxane $\mathrm{B}_{2}$ did not differ between controls and piglets receiving DMTU, GBS failed to increase levels of the prostanoid in treated animals.
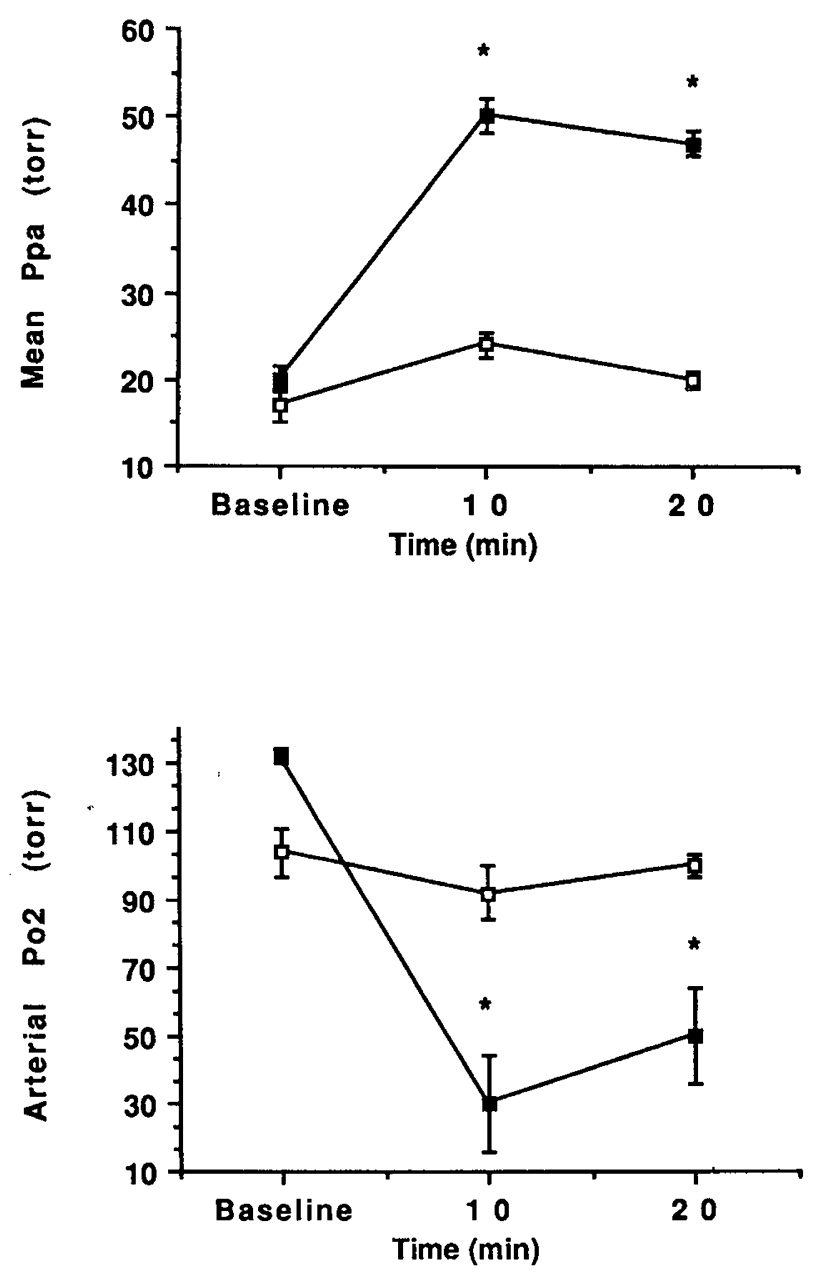

Fig. 1. Changes in mean Ppa (top panel) and arterial $\mathrm{PO}_{2}$ (bottom panel) in infant piglets infused with GBS $\left(10^{8} \mathrm{cfu} / \mathrm{kg} / \mathrm{min}\right.$ for $\left.15 \mathrm{~min}\right)$ in

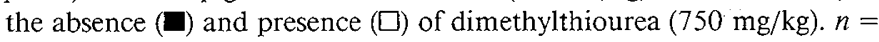
6 for each experimental group. *Significantly $(p<0.05)$ reduced in comparison to piglets not receiving DMTU.

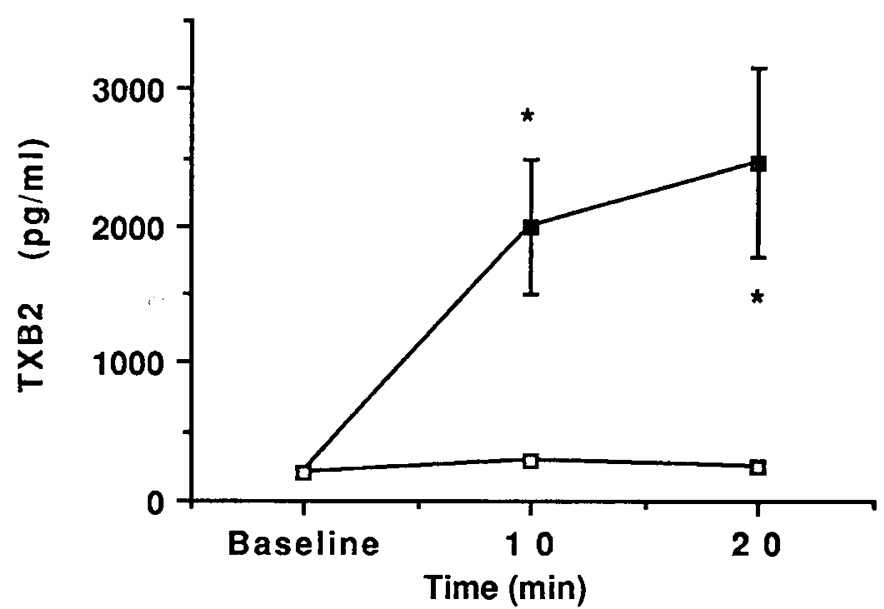

Fig. 2. Changes in blood thromboxane $B_{2}$ levels in infant piglets infused with GBS $\left(10^{8} \mathrm{cfu} / \mathrm{kg} / \mathrm{min}\right.$ for $\left.15 \mathrm{~min}\right)$ in the absence (i) and presence $(\square)$ of DMTU $(750 \mathrm{mg} / \mathrm{kg}) . n=6$ for each experimental group. *Significantly $(p<0.05)$ reduced in comparison to piglets not receiving DMTU.

Additional experiments were conducted to determine if DMTU suppressed changes in Ppa and blood thromboxane $\mathrm{B}_{2}$ content evoked by arachidonic acid. We reasoned that if the protective actions of DMTU noted above were related to direct 
impairment of thromboxane synthesis, either by inhibition of cyclooxygenase or thomboxane synthase, then DMTU should prevent hemodynamic changes and thromboxane $\mathrm{B}_{2}$ accumulation promoted by arachidonic acid, the precursor to thromboxane synthesis. As shown in Figure 3, infusion of arachidonic acid into control piglets increased $\mathrm{Ppa}$ and decreased arterial $\mathrm{PO}_{2}$, with the decline in $\mathrm{PO}_{2}$ occurring slightly after the increase in Ppa. Although the elevated Ppa reverted to baseline values within $5 \mathrm{~min}$, the arterial hypoxia was present when Ppa was normalized and persisted for at least 10 min thereafter. Pretreatment with indomethacin ( $1 \mathrm{mg} / \mathrm{kg}$, i.v.) was, for unexplained reasons, associated with a slight reduction in baseline Ppa. As expected, the cyclooxygenase inhibitor abolished arachidonic acid-induced increases in Ppa and decreases in arterial $\mathrm{PO}_{2}$, thereby confirming the ability of cyclooxygenase blockade to protect against the actions of arachidonic acid infusion. DMTU treatment, initiated
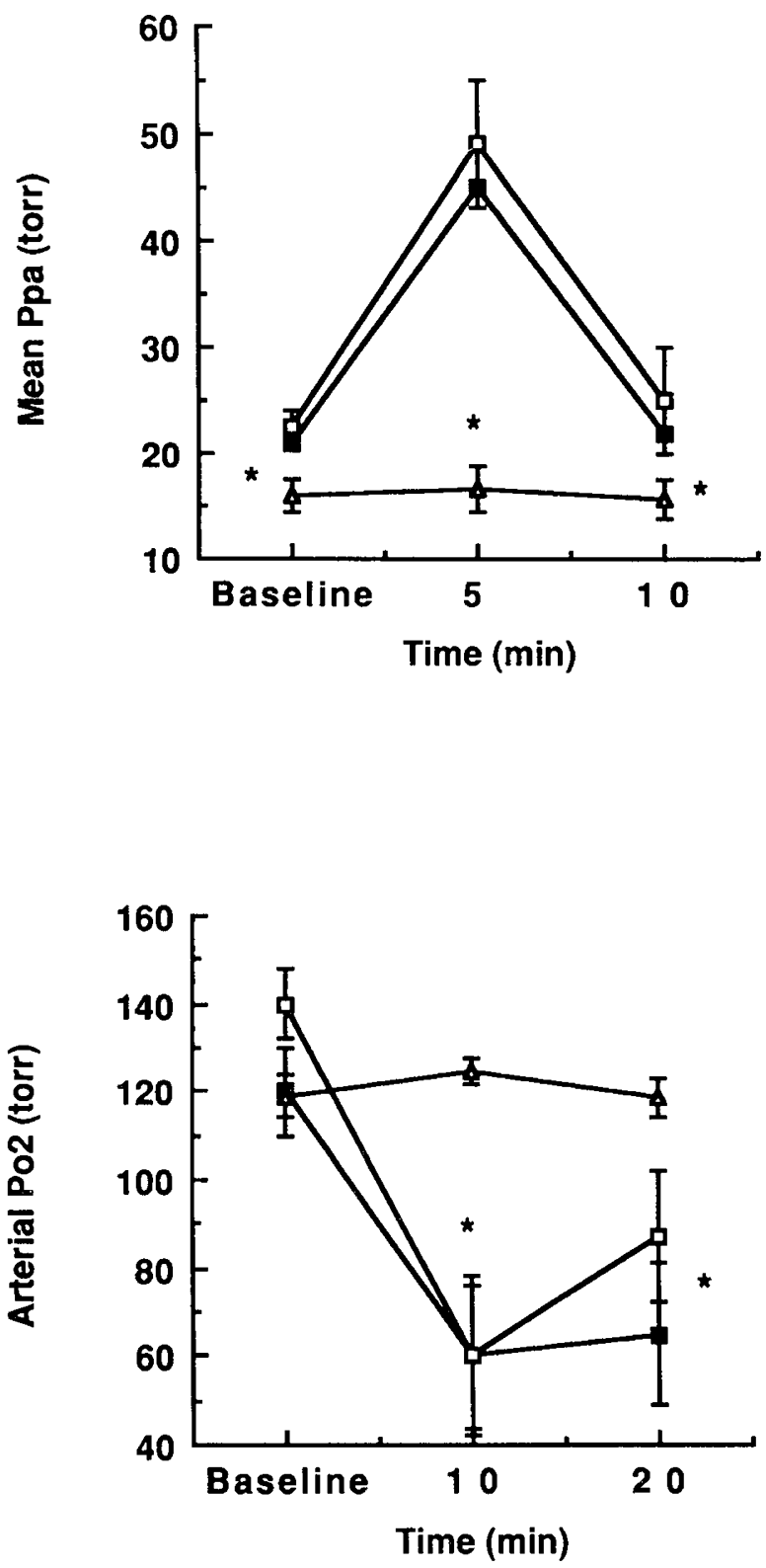

Fig. 3. Changes in mean Ppa (top panel) and arterial $\mathrm{PO}_{2}$ (bottom panel) in infant piglets infused with arachidonic acid (5 mg over $2 \mathrm{~min}$ ) in the absence ( $\square)$ and presence of indomethacin $(\triangle: 1 \mathrm{mg} / \mathrm{kg})$ or dimethylthiourea ( $\square: 750 \mathrm{mg} / \mathrm{kg}$ ). $n=3-5$ for each experimental group. *Significantly inhibited relative to GBS alone or GBS plus DMTU. There were no differences between piglets receiving GBS and piglets receiving GBS plus DMTU.
$15 \mathrm{~min}$ before arachidonic acid, failed to influence either baseline Ppa or arterial $\mathrm{PO}_{2}$. The scavenger also failed to moderate the increase in $\mathrm{Ppa}$ and decrease in arterial $\mathrm{PO}_{2}$ caused by arachidonic acid infusion. Data presented in Figure 4 indicate that increases in Ppa and decreases in arterial $\mathrm{PO}_{2}$ evoked by arachidonic acid were associated with an increased blood content of thromboxane $\mathrm{B}_{2}$. Indomethacin failed to influence baseline contents of the prostanoid but prevented the increase normally evoked by arachidonic acid infusion. Neither baseline thromboxane $\mathrm{B}_{2}$ levels nor the increase associated with arachidonic acid infusion were suppressed by DMTU treatment.

An additional mechanism by which DMTU could protect against GBS-induced pulmonary hypertension is by antagonism of thromboxane $A_{2}$ receptor sites. To test this hypothesis, the ability of DMTU to inhibit increases in Ppa evoked by the thromboxane mimetic, U44069, were examined. We found that 6-min infusions of 100 and $300 \mathrm{ng} / \mathrm{kg} / \mathrm{min}$ U44069 caused doserelated increases in Ppa ( $20 \pm 8$ and $29 \pm 10$ torr, respectively), but that DMTU did not alter either baseline Ppa or the increases normally evoked by U44069 (data not shown)

\section{DISCUSSION}

Previous studies have provided compelling support for involvement of thromboxane in acute phase of infantile sepsis-related pulmonary hypertension (1-3). Blood thromboxane $B_{2}$ levels correlate with the severity of the GBS-induced pulmonary hypertensive response; thromboxane synthesis inhibitors prevent or reverse GBS-induced pulmonary hypertension; and grampositive organisms other than GBS also increase thromboxane levels and promote pulmonary hypertension. In addition to this eicosanoid, studies from our laboratory have suggested that oxygen radicals also may participate in GBS-induced pulmonary hypertension (7). Against this background, the present experiments sought to determine if elaboration of thromboxane in the setting of GBS sepsis was dependent on free radical accumulation.

An important observation of our study is that DMTU attenuates GBS-induced increases in Ppa and arterial hypoxemia, as we have previously reported (7), and also prevents accumulation of thromboxane $B_{2}$ in systemic blood. Although this finding suggests that accumulation of thromboxane might be free-radical dependent, we also considered the possibilities that DMTU could be acting as an inhibitor of cyclooxygenase and/or thromboxane synthase or that the scavenger could antagonize thromboxane at its end-organ receptors. To examine the first option, we infused the precursor to thromboxane, arachidonic acid, and determined if DMTU influenced the ensuing pulmonary response and accumulation of thromboxane $B_{2}$. This appeared to be a reasonable strategy based on earlier reports by Hyman et al. (11) indicating that rapid i.v. bolus infusions of arachidonic acid into intact cats

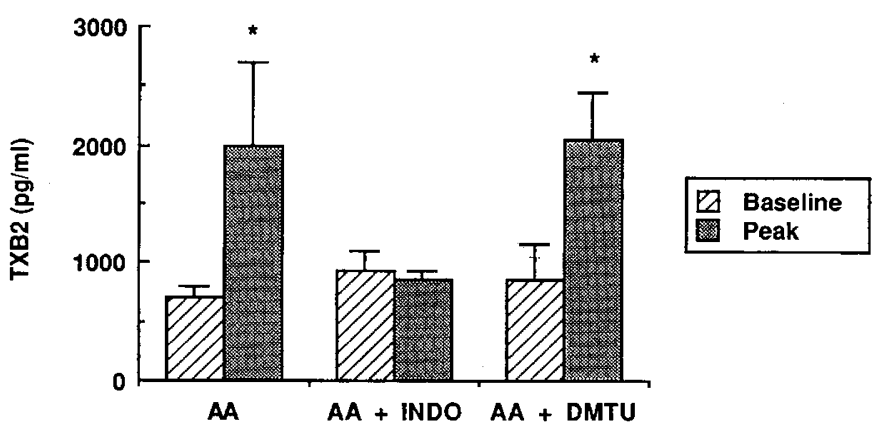

Fig. 4. Changes in blood thromboxane $B_{2}$ levels in infant piglets before and after infusion of arachidonic acid ( $5 \mathrm{mg}$ over $2 \mathrm{~min}$ ) in the absence and presence of indomethacin (INDO: $1 \mathrm{mg} / \mathrm{kg}$ ) or DMTU $(750$ $\mathrm{mg} / \mathrm{kg}$ ). $n=3-5$ for each experimental group. There were no significant differences between control piglets and piglets receiving DMTU either in the baseline state or after infusion of arachidonic acid. 
promoted thromboxane-dependent pulmonary vasoconstriction. In addition, we confirmed the involvement of cyclooxygenase by demonstrating that arachidonic acid-induced changes in both $\mathrm{Ppa}$ and arterial $\mathrm{PO}_{2}$ were abolished by indomethacin. In the context of our study, we found that DMTU did not alter either the arachidonic acid-induced increase in blood thromboxane $\mathrm{B}_{2}$ or the attendant increase in Ppa and decreases in $\mathrm{PO}_{2}$. To determine if DMTU acted as an end organ antagonist of thromboxane receptors, we used the thromboxane mimetic, U44069, a stable epoxymethano-analogue of $\mathrm{PGH}_{2}$ believed to interact with the thromboxane receptor to promote contraction of isolated smooth muscle preparations (11). Similar to results of experiments with arachidonic acid as the provocative agent, DMTU also failed to attenuate increases in Ppa promoted by U44069. Collectively, these findings demonstrate that the protective effects of DMTU in GBS-induced pulmonary hypertension cannot be ascribed to inhibition of enzymes involved with thromboxane synthesis or to blockade of thromboxane receptors on target smooth muscle cells. Keeping in mind the limited information regarding the selectivity of DMTU as a free radical scavenger, results of our study suggest that induction of thromboxane synthesis by GBS is oxygen radical-dependent. Furthermore, inasmuch as DMTU is reasonably specific for hydroxyl radical $(5,6)$, as opposed to its precursors, superoxide anion and hydrogen peroxide, our observations point to hydroxyl radical as an immediate cause of thromboxane synthesis in the setting of GBS sepsis.

Considerable evidence suggests that oxygen-derived free radicals can promote arachidonic acid metabolism. Introduction of chemical oxygen radical-generating systems (e.g. xanthine plus xanthine oxidase or glucose plus glucose oxidase) to medium perfusing isolated lung preparations results in the appearance of arachidonic acid metabolites, including thromboxane, in lung perfusion medium $(12,13)$. Blockade of arachidonic acid metabolism in these systems attenuates increases in lung water and pulmonary vascular resistance, thus indicating that the actions of oxygen radicals were mediated in part by arachidonic acid metabolites. The mechanism by which oxygen radicals promote arachidonic acid metabolism has yet to be defined, but it has been known for some time that free radicals can attack membrane lipids and release arachidonic acid (14) or induce cyclooxygenase (15), and thereby promote synthesis of eicosanoids. Based on these considerations, we suggest that the protective effects of DMTU in piglets infected with GBS is related to inhibition of an early step in arachidonic acid metabolism, probably arachidonic acid release, which occurs secondarily to free radical accumulation. Additional studies, possibly using cell culture systems, will be necessary to test this hypothesis.

Generation of toxic oxygen radicals appears to be a characteristic response to sepsis or endotoxemia (16). An interesting question to emerge relates to the functional importance of free radical generation in the setting of GBS sepsis. Traditional pathogenic concepts suggest that free radical generation by pulmonary intravascular cells may be an important component of hostdefense against bacteria. In support of this contention, we have found that GBS is avidly sequestered and killed in the lungs of infant piglets (17). Electron microscopy indicated that the organisms were localized exclusively within pulmonary intravascular macrophages, though other populations of phagocytes also may participate in the response to GBS. As with other cells of the reticuloendothelial system, pulmonary intravascular macrophages exhibit profound phagocytic activity (18) and are capable of generating a spectrum of arachidonic acid metabolites (19). We have reported that DMTU attenuates killing of GBS in the lungs of infant piglets as well as abolishing the adverse hemodynamic complications (20). Based on these considerations, we propose that activation of an oxygen radical-dependent host microbicidal mechanism plays a key role early in the response to GBS by initiating generation of thromboxane $A_{2}$. Many elements of this hypothesis remain untested, but it may provide a useful framework for future studies.

\section{REFERENCES}

1. Runkle B, Goldberg RN, Streitfeld MM, Clark MR, Buron E, Setzer ES, Bancalari E 1984 Cardiovascular changes in group B streptococcal sepsis: relationship to prostacyclin and thromboxane $\mathrm{A}_{2}$. Pediatr Res 18:874-878

2. Truog WE, Sorenson GK, Standaert TA, Redding GJ 1986 Effects of a thromboxane synthesis inhibitor, dazmegrel (UK 38,485 ) on pulmonary gas exchange and hemodynamics in neonatal sepsis. Pediatr Res 20:481-486

3. Gibson RL, Truog WE, Redding GJ 1988 Thromboxane associated pulmonary hypertension in three types of gram positive bacteremia in piglets. Pediatr Res 23:553-556

4. Goldberg RN, Suguihara C, Streitfeld MM, Bancalari A, Clark MR, Bancalari E 1986 Effects of a leukotriene antagonist on the early hemodynamic manifestations of group B streptococcal sepsis in piglets. Pediatr Res 20:1004-1008

5. Fox RB 1984 Prevention of granulocyte-mediated oxidant lung injury in rats by a hydroxyl radical scavenger, dimethylthiourea. J Clin Invest 74: 14561464

6. Wasil M, Halliwell B, Grootveld M, Moorehouse CP, Hutchison DCS, Baum H 1988 The specificity of thiourea, dimethylthiourea, and dimethylsulfoxide as scavengers of hydroxyl radicals. Their protection of $\alpha_{1}$-antiproteinase against inactivation by hypochlorous acid. Biochem J 243:867-870

7. Pauly TH, Bowdy BD, Haven CA, Barr SB, Gillespie MN 1988 Evidence for hydroxyl radical involvement in group B streptococcus-induced pulmonary hypertension and arterial hypoxemia in young piglets. Pediatr Res 24:739745

8. Bernard GR, Lucht WD, Niedermeyer ME, Snapper JR, Ogletree ML, Brigham $\mathrm{KL} 1984$ Effect of $\mathrm{N}$-acetylcysteine on the pulmonary vascular response to endoxin in the awake sheep and upon in vitro granulocyte function. $\mathrm{J}$ Clin Invest 73:1772-1784

9. Tai H-H, Yuan B 1978 Development of radioimmunassay for thromboxane $B_{2}$. Anal Biochem 87:343-349

10. Coleman RA, Humphrey PPA, Kennedy I, Levy GP, Lumley P 1981 Comparison of the actions of $\mathrm{U} 46610$, a prostaglandin $\mathrm{H}_{2}$-analogue, with those of prostaglandin $\mathrm{H}_{2}$ and thromboxane $\mathrm{A}_{2}$ on some isolated smooth muscle preparations. Br J Pharmacol 73:773-778

11. Hyman AL, Spannhake EW, Kadowitz PJ 1980 Divergent responses to arachidonic acid in the feline pulmonary vascular bed. Am J Physiol 239:H40$\mathrm{H} 46$

12. Tate RM, Vanbenthuysen KM, Shasby DM, McMurtry IF, Repine JE 1982 Oxygen radical-mediated permeability edema and vasoconstriction in isolated rabbit lungs. Am Rev Respir Dis 126:802-806

13. Gillespie MN, Moore CG 1987 Salutary effects of prostaglandin $E_{1}$ in hydrogen peroxide-induced lung injury. J Pharmacol Exp Ther 241:1-5

14. Tapel AL 1973 Lipid peroxidation damage to cell components. Fed Proc 32:1870-1874

15. Hemler ME, Cook HW, Lands WEM 1979 Prostaglandin biosynthesis can be triggered by lipid peroxides. Arch Bioch Biophys 193:340-345

16. Brigham KL 1986 Role of free radicals in lung injury. Chest 89:859-863

17. Bowdy BD, Aziz SM, Marple SL, Yoneda K, Pauly TH, Coonrod JD, Gillespie MN 1990 Organ-specific disposition of group B streptococci in piglets: evidence for a direct interaction with target cells in the pulmonary circulation. Pediatr Res (in press)

18. Winkler GC 1988 Pulmonary intravascular macrophages in domestic animal species: review of structural and functional properties. Am J Anat 181:217234

19. Bertram TA, Overby LH, Danilowicz R, Eling TE, Brody AR 1988 Pulmonary intravascular macrophages metabolize arachidonic acid in vitro. Am Rev Respir Dis 138:936-944

20. Bowdy BD, Marple SL, Pauly TH, Coonrod JD, Gillespie MN 1990 Oxygen radical dependent bacterial killing and pulmonary hypertension in piglets infected with group B streptococci. Am Rev Respir Dis (in press) 